International Journal of Engineering \& Technology, $7(4.5)(2018) 722-727$
SPC
International Journal of Engineering \& Technology
Website $\frac{w w w . s c i e n c e p u b c o . c o m / i n d e x . p h p / I J E T}{2}$
Research paper

\title{
A study on fatigue life of RC bridge and its improvement methods
}

\author{
Neha B ${ }^{1 *}$, Sruthy $\mathbf{S}^{2}$, Rahul T. $\mathbf{M}^{3}$ \\ ${ }^{1}$ Post graduate student, Department of Civil Engineering, Amrita School of Engineering, Coimbatore, Amrita Vishwa Vidyapeetham, \\ India 641112 \\ ${ }^{2}$ Assistant professor, Department of Civil Engineering, Amrita School of Engineering, Coimbatore, Amrita Vishwa Vidyapeetham, India \\ 641112 \\ ${ }^{3}$ Assistant professor, Department of Civil Engineering, Amrita School of Engineering, Coimbatore, Amrita Vishwa Vidyapeetham, India \\ 641112 \\ *Corresponding author E-mail: s_sruthy@cb.amrita.edu
}

\begin{abstract}
Fatigue is a crucial factor which affects the total life and serviceability of highway bridges. There are several factors that contribute to the development of fatigue in RC bridges. Among them, traffic loads, wind loads and corrosion of reinforcement are some of the important factors to name a few. In order to address these fatigue issues and improve the fatigue life of highway bridges, many improvement methods have been suggested in the literature. This study attempts to investigate the effectiveness of various improvement methods suggested in the literature. The improvement methods that has been included in this study are externally bonded reinforcement and deck overlay. To accomplish the objective, an existing highway bridge was selected based on the structural details and traffic data and then various improvement methods were applied to analyze its improvement in fatigue life. For analysis, an embedded reinforcement modeling was carried out in ANSYS followed by a nonlinear analysis in ANSYS workbench. The results of the study were found to be in alignment with AASTHO LRFD (2007), IRC SP 60(2002), IRC 6 (2014), IRC SP 37 (2010) and IRC 37 (2012) codal provisions.
\end{abstract}

Keywords: ANSYS Workbench; Carbonation; Deck Overlay; Externally Bonded Reinforcement; Fatigue; Palm-Gren Miner's Rule.

\section{Introduction}

Highway bridges are subjected to variability in traffic load, wind load and corrosion of reinforcement, which results in deterioration of the deck. Fatigue is one of the crucial forms of deterioration which can arise due to accumulation of damage. Primarily, Fatigue occurs when the structure is subjected to repeated cycles of loading and unloading during the designed life. Followed by this, variable amplitude of dynamic loading from traffic and deterioration on the road surface leads to damage accumulation on the structure. This damage further develops into micro cracks and brings in serious fatigue failure of the bridge.

In addition to traffic loading, the bridge deck is also exposed to several aggressive environmental conditions which add on to fatigue development. This phenomenon of fatigue development arising out of the combined effect of corrosive environment and dynamic vehicle loading on the structure is referred as corrosion fatigue. Therefore, it is essential to analyze the combined effect of corrosion and fatigue on the structure.

Scanning the literature, we found that many studies in literature have discussed the fatigue behavior of bridges. YongSheng et al (2013) and Wand et al (2016) studied the fatigue design of steel bridges whereas Habeeba et al (2015) investigated the fatigue life of reinforced concrete bridge. The study used ANSYS and SAP 2000 software with S-N curve and found that the results are in accordance with IRC specification. Similarly, Zhang et al (2014) studied the effect of corrosion fatigue arising out of dynamic vehi- cle load and suggested that the action could bring major threat to the functionality and safety of the structure.

Seon Ji et al (2011) analyzed the static and fatigue behavior of composite sandwich bridge deck made up of hybrid GFRP steel core and compared the laboratory test results with the ANSYS software. The results suggested that the GFRP steel core in bridge decks improves the buckling response and stiffness. Kong et al (2013) studied the thermal behavior of steel and concrete bridges and evaluated the thermal variation. The study found that the temperature gradient increases the deflection in the bridge deck and as a result thermal stresses are developed at the interface of the GFRP panel bridge. Yohannan et al (2015), El-Ragaby et al (2007), and Kurian et al (2013) discussed the fatigue behavior of bridge deck made up of FRP materials and concluded that FRP material is effective for strengthening of the bridge deck panels. Ellobody et al (2011) studied the performance of composite girder with CFRP laminates and suggested that CFRP laminates increase the strength, durability and load capacity of the composite girders. Similarly, Puurula et al (2014) analyzed the failure of RC Railway Bridge and investigated the strength of the bridge using CFRP bars and found the increase in strength of the structure with CFRP. In similar lines, Mini et al performed an experiment on strengthening RC beam with GFRP sheets and compared the efficiency of GFRP wrapped beams and un wrapped beam. The study found that the load carrying capacity is better for beam wrapped with GFRP sheets.

This study attempts to assess the effectiveness of various methods proposed in the literature to improve the fatigue life of reinforced concrete bridge. We use the stress based approach to analyze the 
fatigue of RC bridge. S-N curve has been used to generate the relation between the fatigue life and stress level and ANSYS has been used to model the fatigue of the bridge. The fatigue life has been determined using Miner's rule and the deterioration due to carbonation has been analyzed. Following this, different methods for fatigue life improvement are applied on the ANSYS model of the bridge and the effectiveness of each method has been captured.

\section{Methodology}

The objective of the study is to measure the fatigue life of a reinforced concrete bridge and to suggest the improvement methods to enhance the fatigue life. The study was conducted on a highway bridge at Menonpara, Palakkad district. Structural details of the bridge were collected from PWD, Kozhinjampara. A traffic study was conducted to find out the traffic load on the bridge. Embedded model of reinforcement was used to model the bridge in ANSYS and fatigue analysis was carried out with the help of S-N curves. A study on effect of deterioration due to carbonation was also conducted to assess the fatigue damage. Based on the results, improvement methods were suggested. The effectiveness of the methods was then evaluated by reanalyzing the impact of these methods on the highway bridge in ANSYS. The fatigue life is calculated from the traffic data using Miner's rule.

\section{Structural details of bridge}

The bridge selected for this study is a reinforced concrete bridge at Menonpara built over the_Korayar River in Palakkad district (10.7964453, 76.7798598). The bridge connects Nattukal and Velanthavalam village on roadways and its construction was accomplished in December 2013._Figure1 shows the location of the bridge.

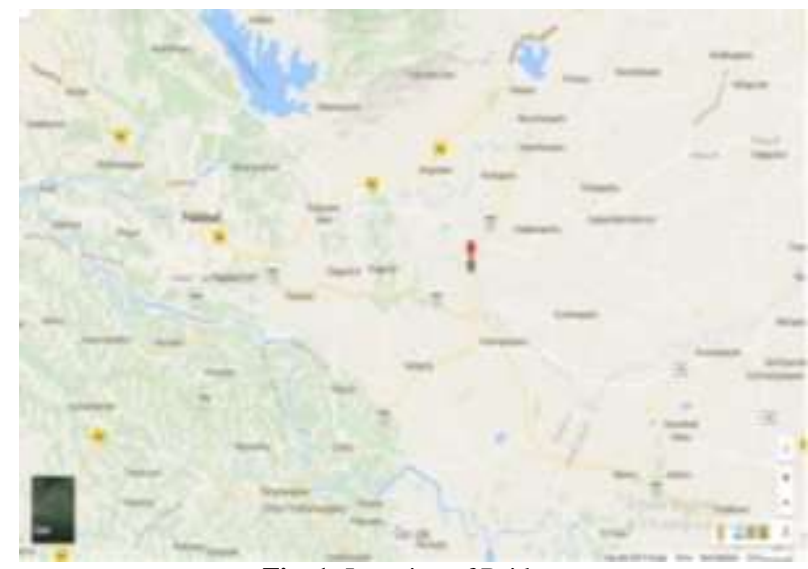

Fig. 1: Location of Bridge.

The bridge ( $\mathrm{SH} 26$ ) has a carriageway width of $7.5 \mathrm{~m}$, footpath width of $1.5 \mathrm{~m}$ on either side and three spans with $25.32 \mathrm{~m}$ each. The bridge consists of three longitudinal and four cross girders. It is a RCC T beam bridge across the river. The concrete and steel used in the bridge are M20 grade and Fe415 respectively. For the deck slab, a $25 \mathrm{~mm}$ cover is provided and for the girders, a $40 \mathrm{~mm}$ cover is provided. Figure 2 depicts the cross sectional details of the bridge.

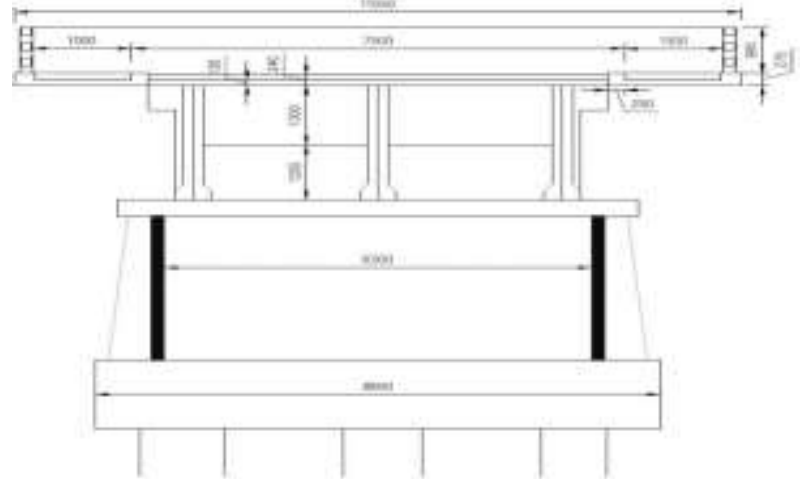

Fig. 2: Cross Sectional Details of Bridge.

\section{Traffic study}

The data on volume of traffic on the bridge was collected by noting the traffic flow on the bridge from Athicode junc- tion over a week. Though the traffic was found to be a mixed type, truck traffic was found to be more predominant because the bridge served as one of the State Highway con- necting Palakkad and Coimbatore district.

The average daily truck traffic (ADTT) on the bridge was found to be 1510 trucks/day. For the analysis the stress cy- cles are assumed as one cycle per truck during its design life. In order to convert the different axle load repetitions to an equivalent single axle load, the equivalency factor was computed using the following equation. The conversion has been performed following IRC 37 (2012).

$$
\mathrm{EF}=\left(\frac{\text { Axie loond }}{\text { standard axie load }}\right)^{4}
$$

The load for different axle with different tyre configuration was taken following IRC SP 37(2010). As per IRC 6 2014, IRC class A wheeled vehicle was considered as the stand- ard vehicle load. The maximum axle load due to IRC class A vehicle was assumed to be the standard axle load for analysis. A depiction of IRC class A wheeled vehicle is provided in figure 3 .

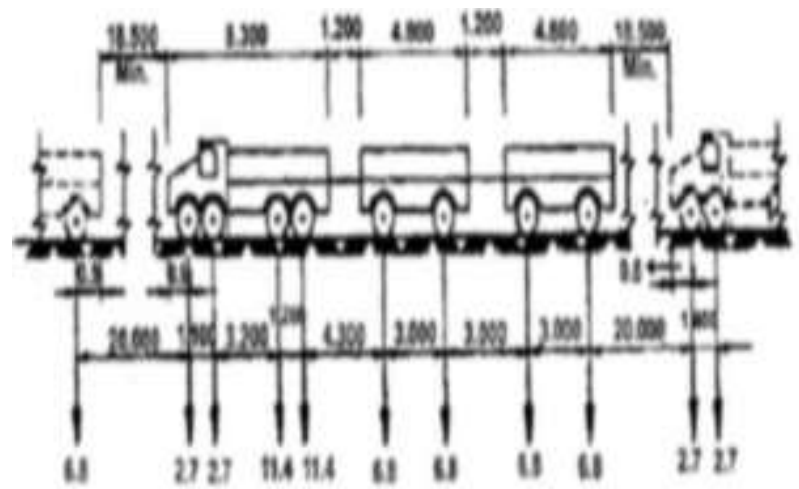

Fig. 3: Standard IRC Class A Wheeled Vehicle (IRC 6 2014).

\section{Fatigue analysis using palm-GREN miner's rule}

The evaluation of fatigue in the bridge depends on two primary factors. First, the dynamic load on the bridge and second the material property of the bridge. The periodic loading on the bridge is the simplest of all fatigue load process and is defined as constant amplitude load cycle in ANSYS. The constant amplitude fatigue test result is usually represented as S-N curve where $\mathrm{S}$ represents the stress range and $\mathrm{N}$ represents the number of cycles of failure. Famous researcher Palm - gren Miner used SN curve to calculate the cumulative damage of the bridge due to a single stress range cycle. Then, he used these SN curves to formulate linear damage accumulation rule. 
Since, the variable stress ranges on the bridge causes fatigue damage, the data on number of stress cycles that the bridge undergoes is essential for assessment of fatigue damage. As per Miner's rule, the calculation of fatigue damage is given below,

$D=\sum_{i=1}^{m} \frac{m_{i}}{N_{i}}$

Where

$n_{i=}$ Number of stress cycles for different stress ranges

$N_{i}=$ Number of stress cycles causes failure corresponding to observed stress ranges

As per AASTHO LRFD Bridge design specifications, the number of stress cycles induced by different vehicles is calculated as follows.

$n_{\mathrm{i}}=365$. Y.n. $(A D T T)_{\mathrm{sL}}$

Where

$(A D T T)_{s L}$ The number of trucks per day in a single lane $=\mathrm{p}$ (ADTT)

$\mathrm{ADTT}=$ the number of trucks per day in one direction

$\mathrm{p}=\mathrm{a}$ factor reflecting the number of lanes available to trucks $\mathrm{Y}=$ design life in years

$\mathrm{n}=$ number of cycles that take place at stress range level

In this study, the value of $\mathrm{p}$ and $\mathrm{n}$ is taken as per AASTHO recommendation.

Based on 75 years of $(A D T T)_{\text {s }}$ in AASTHO LRFD [1] bridge design specifications, a graphical representation of stress range versus number of cycles is provided in Figure 4. From this S-N curve, the number of stress cycles that result in failure is calculated for the observed stress ranges.

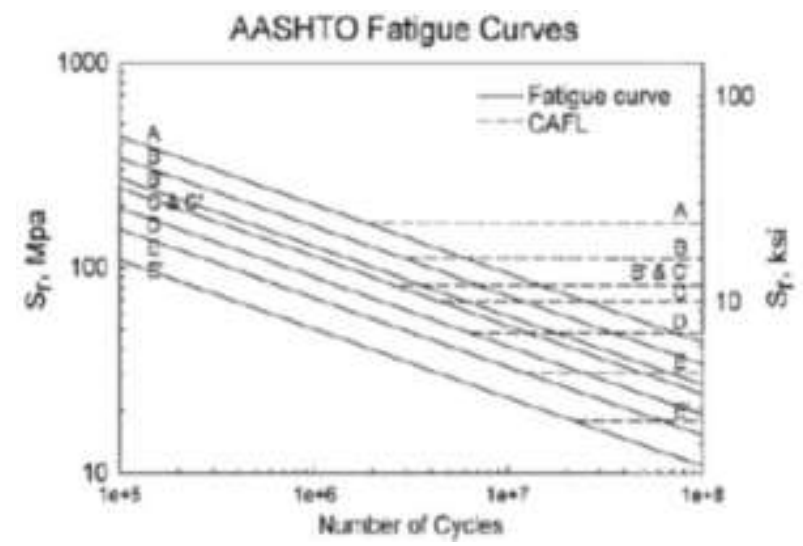

Fig. 4: Stress Ranges versus Number of Cycles (AASTHO LRFD)

As per the equation 3 , the observed number of stress cycles for various vehicles on a bridge with 75 years of design life is shown in table 1 .

\begin{tabular}{ll}
\multicolumn{1}{c}{ Table 1: Observed Number of Stress Cycles } \\
\hline Vehicles & $\boldsymbol{n}_{\boldsymbol{i}}(\mathrm{cycles} / \mathrm{year})$ \\
\hline Bus & $21.2 \times 10^{\wedge} 6$ \\
Medium truck & $19.8 \times 10^{\wedge} 6$ \\
Heavy truck & $12.2 \times 10^{\wedge} 6$ \\
Very heavy truck & $8.6 \times 10^{\wedge} 6$ \\
\hline
\end{tabular}

From the S-N curve, the number of stress cycles corresponding to the observed stress range was found to be $10^{\wedge} 6$ for each category of vehicles. Upon inserting the values in Palm-gren Miner's rule, the cumulative damage was found to be 0.618 per year. Therefore, the remaining life of the bridge came out to be approximately 1.62 years and the total life of the bridge is about 77 years.

\section{Fatigue analysis-using ANSYS}

To analyze the fatigue of the bridge, first a single span of the bridge deck slab was modeled in CAD 2012 and then the design was imported to ANSYS workbench 16.1. The CAD drawing of the bridge deck is shown in figure 5. Due to the complexity of the structure, one sixth of the span was considered for analysis which represents that a length of $4.4 \mathrm{~m}$, width $3.75 \mathrm{~m}$ and thickness $0.275 \mathrm{~m}$ was considered for analysis. As per the structural specifications, the girder beams were provided as a solid concrete beam element for support.

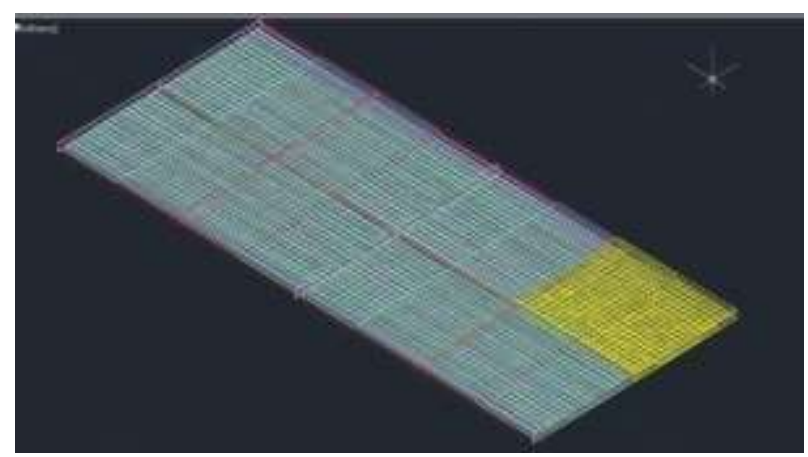

Fig. 5: Model in CAD.

According to finite element analysis of reinforced concrete, three methods viz. discrete, embedded and smeared model are adopted to model steel reinforcement. However, for large scale model, the complexity increases during the analysis. Therefore, embedded reinforcement model is considered as advantageous for complex reinforcements. Embedded reinforcement model analyzes the steel reinforcements distinctly without integrating it with concrete elements. In this study, embedded model of reinforcement was used to get an accurate fatigue damage value. The reinforcement model and solid model of the bridge used for the analysis in ANSYS workbench is presented in figure 6 and 7 respectively.

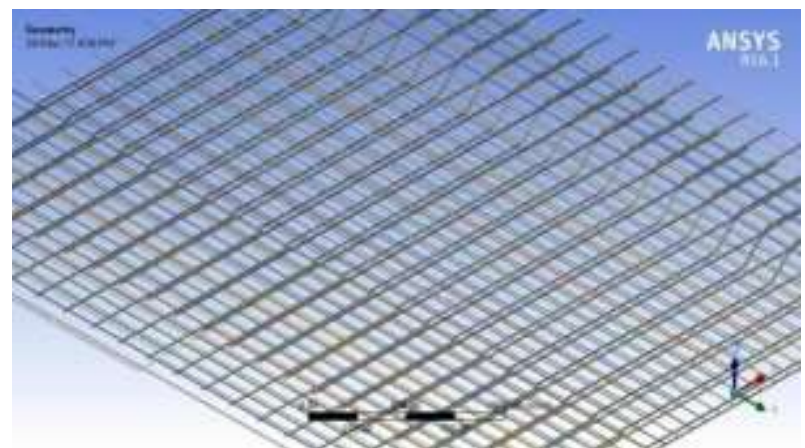

Fig. 6: Reinforcement Model in ANSYS.



Fig. 7: Solid Model in ANSYS. 
The modeled deck slab was meshed, and it consists of 5553 nodes and 2121 elements. Then the load was applied as per the actual traffic condition. Fatigue of a bridge is caused mainly due to the repeated cycles of loading and unloading during the design life. Therefore, for static structural nonlinear analysis in ANSYS, the loading on the structure is applied for every five minutes. Figure 8 shows the equivalent stress on the bridge deck.



Fig. 8: Equivalent Stress.

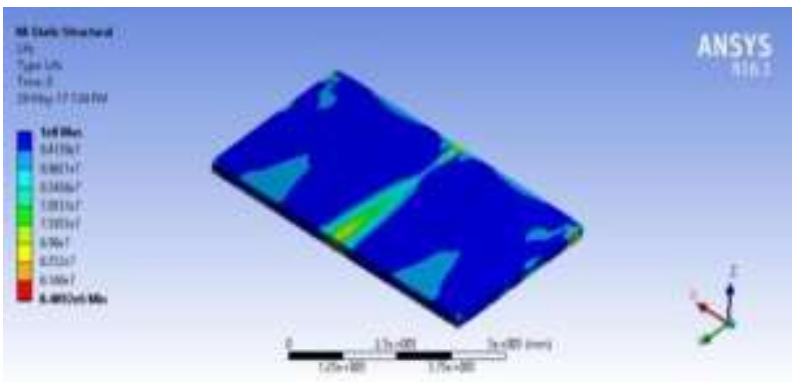

Fig. 9: Fatigue Life Cycle.

After tracking the equivalent stress, the fatigue analysis of the deck slab was carried out by applying the S-N curve. The analysis was continued till the model failed. As a result, the result of the study was obtained in terms of fatigue life. The results of the analysis in ANSYS revealed that the minimum fatigue life cycle of the bridge is 8.4 million during the design life considering the current traffic condition. The fatigue life distribution represents the maximum and minimum life of the bridge in terms of number of cycles and is shown in figure 9.

\section{Study on deterioration of $\mathrm{RC}$ bridge due to carbonation}

Fatigue in bridges can also happen because of aggressive environmental situations, the phenomenon of fatigue formation due to the combined effect of corrosive environment and continuous vehicle loading on the structure is referred as corrosion fatigue. Corrosion fatigue involves the physical, chemical and environmental changes which results in degradation and reduction in the performance of the structure. One such instance is corrosion in the structure because of aggressive carbonation of air constituents.

In such cases, the carbon dioxide in air reacts with hydrated minerals in the concrete and lowers the $\mathrm{pH}$ value of the carbonated zone. Usually, carbonation zone initiates from the surface of exposed concrete. Corrosion due to carbonation depends on several factors and the amount and time that the carbonation zone takes to reach the reinforcement depends on thickness of concrete cover, concrete porosity, presence and extent of crack, humidity level and the level of exposure of carbon dioxide.

As per IRC SP 60 2002[2], the propagation time of corrosion in years can be calculated using the following formula: -

$t_{1}=\frac{\operatorname{son}}{\sin }$

Where

$$
\begin{aligned}
& t_{1}=\text { the propagation time of corrosion (years) } \\
& r=\text { the rate of corrosion }(\mu \mathrm{m} / \text { year }) \\
& \mathrm{C}=\text { the thickness of the concrete cover }(\mathrm{mm}) \\
& \mathrm{D}=\text { the diameter of the reinforcement bar }(\mathrm{mm})
\end{aligned}
$$

The corrosion rate of concrete depends on the environmental factors such as temperature, humidity etc. In addition, IRC SP 60 2002 provides the relationship between the extent of cover and the age at which the corrosion starts for M25, M35 and M45 concrete. The relationship is shown in figure 10.



Fig. 10: Concrete Cover vs Time to Start Carbonation Induced Corrosion Source: IRC SP 602002.

It has been observed that the carbonation induced corrosion is more predominant in structures that_is either situated near industrial areas, concrete with high porosity or is made up of low concrete cover. Therefore, in bridge like structures, a good quality of concrete cover with sufficient thickness should be provided to avoid carbonation for 100 years. In this study, the bridge is located in a region where the humidity is about $78-80 \%$. Therefore, propagation of carbonation corrosion for $12 \mathrm{~mm}$ and $8 \mathrm{~mm}$ diameter bars with M20 concrete, $25 \mathrm{~mm}$ thickness concrete cover was found to be 84 and 125 years respectively. However, the total life of the bridge due to the vehicle load was found to be approximately 77 years. Hence the study infers that there will not be much effect on the rate of carbonation corrosion during the design life of the case bridge.

\section{Fatigue life improvement methods}

Due to large number of heavy truck traffic and corrosion, the performance of bridge becomes less satisfactory. The bridge structures often need to carry large loads during their design life and hence it is necessary to improve their capacity for functionality and safety. The methods considered in this study to improve the life of the bridges are listed below

- Externally bonded reinforcement

- Deck overlays

\subsection{Materials for the improvement methods}

There are different types of materials that are used as externally bonded reinforcement and deck overlays to increase the fatigue life of a bridge. In this project, Fiber Reinforce Polymer (FRP), Polyethylene terephthalate (PET) and Polymer concrete overlay materials are used to enhance the life of the $\mathrm{RC}$ bridge. Based on the fiber, the most common type of FRPs that is used for structural applications are Aramid Fiber Reinforced Polymer (AFRP), Glass Fiber Reinforced Polymer (GFRP) and Carbon Fiber Reinforced Polymer (CFRP). In this study, the GFRP and CFRP sheets are used as both externally bonded reinforcement and deck overlay. The PET bottle waste and Polymer concrete overlays consisting of epoxy polymer, polyester polymer and methacrylate Polymer are 
also applied as deck overlay. The properties of the materials used for the improvement methods are mentioned in the table 2, table 3, table 4, table 5, table 6 and table 7 .

Table 2: Properties of GFRP

\begin{tabular}{lll}
\hline Properties & Longitudinal & Transverse \\
\hline $\begin{array}{l}\text { Density }\left(\mathrm{g} / \mathrm{cm}^{\wedge} \text { ) }\right. \\
\text { Tensile Strength }(\mathrm{MPa})\end{array}$ & 2 & 2 \\
$\begin{array}{l}\text { Young's Modulus } \\
\text { (MPa) }\end{array}$ & 1600 & 1600 \\
$\begin{array}{l}\text { Shear Modulus } \\
\text { (MPa) }\end{array}$ & 76000 & 42000 \\
Poisson's ratio & 59280 & 30912 \\
\hline
\end{tabular}

Source: ACI 440.2R-08 (2002).

Table 3: Properties of CFRP

\begin{tabular}{lll}
\hline Properties & Longitudinal & Transverse \\
\hline Density $\left(\mathrm{KN} / \mathrm{m}^{\wedge}\right)$ & 17.3 & 17.3 \\
Tensile Strength $(\mathrm{MPa})$ & 3500 & 3500 \\
Young's Modulus $(\mathrm{MPa})$ & 230000 & 17900 \\
$\begin{array}{l}\text { Shear Modulus } \\
\text { (MPa) }\end{array}$ & 11790 & 6880 \\
Poisson's ratio & 0.22 & 0.30 \\
\hline Source:
\end{tabular}

Source: ACI 440.2R-08 (2002).

Table 4: Properties of PET

\begin{tabular}{ll}
\hline Properties & Values \\
\hline Poisson's ratio & 0.44 \\
Tensile Modulus $(\mathrm{GPa})$ & 3 \\
Tensile Strength $(\mathrm{GPa})$ & 80 \\
Density $\left(\mathrm{g} / \mathrm{cm}^{\wedge}\right)$ & 1.4 \\
\hline
\end{tabular}

Density $\left(\mathrm{g} / \mathrm{cm}^{\wedge}\right)$

Source: Sahil Verma Et Al (2015).

Table 5: Properties of Epoxy Polymer

\begin{tabular}{ll}
\hline \multicolumn{2}{c}{ Table 5: Properties of Epoxy Polymer } \\
\hline Properties & Values \\
Tensile Modulus ratio $(\mathrm{MPa})$ & 0.25 \\
Tensile Strength $(\mathrm{MPa})$ & $4-8.3 \times 10^{\wedge 2}$ \\
Density $\left(\mathrm{g} / \mathrm{cm}^{3}\right)$ & 14 \\
\hline Souce & 1.4 \\
\hline
\end{tabular}

Source: Nuno Gama (1999).

Table 6: Properties of Polyester Polymer

\begin{tabular}{ll}
\hline Properties & Values \\
\hline Poisson's ratio & 0.25 \\
Tensile Modulus $(\mathrm{MPa})$ & $2.4-6.2 \mathrm{X} 10^{\wedge 2}$ \\
Tensile Strength $(\mathrm{MPa})$ & 14 \\
Density $\left(\mathrm{g} / \mathrm{cm}^{\wedge} 3\right)$ & 1.37 \\
\hline
\end{tabular}

Source: Nuno Gama (1999).

Table 7: Properties of Methacrylate polymer

\begin{tabular}{ll}
\hline Properties & Values \\
\hline Poisson's ratio & 0.4 \\
Tensile Modulus $(\mathrm{GPa})$ & $7 \mathrm{X} 10^{\wedge 2}$ \\
Tensile Strength $(\mathrm{MPa})$ & $3-8$ \\
Density $\left(\mathrm{g} / \mathrm{cm}^{3}\right)$ & 1.18 \\
\hline
\end{tabular}

Source: Nuno Gama (1999).

\subsection{Analysis for the effectiveness of improvement meth- ods}

\subsubsection{Externally bonded reinforcement}

The strength of an existing RC structure can be improved by providing externally bonded reinforcement which can form a bonding with high tensile strength and stiffness to the tension side of the element. The GFRP and CFRP materials are applied at a thickness of $2 \mathrm{~mm}$ on the tension side. This served, as an external reinforcement to the original bridge. The engineering properties of the materials along with the $\mathrm{S}-\mathrm{N}$ curve were then given as input to ANSYS workbench. Then the reanalysis was performed to assess the improvement in fatigue life. . The results demonstrated that the minimum fatigue life cycle increased to 37 million cycles after application of CFRP and GFRP as externally bonded reinforcement.

\subsubsection{Deck overlay}

Overlay approach is considered as a good method to protect and extend the service life of the bridge deck. Different polymeric overlays such as epoxy polymeric, polyester polymeric and methacrylate polymeric overlays are applied at a thickness of $8 \mathrm{~mm}$ to the original bridge model.-In addition, the Fiber reinforced polymers such as CFRP and GFRP are incorporated at a thickness of $2 \mathrm{~mm}$. The structure was then analyzed in ANSYS workbench. The results showed that the application of CFRP, GFRP, PET bottles and the polymeric overlays of epoxy and polyester increased the minimum fatigue life cycles to 37 million and the methacrylate polymeric overlay increased the fatigue life cycle to 38 million cycles. In this paper, thermoplastic polymer PET bottle wastes were also applied as deck overlay as a part of waste management. Figure 11 shows the increase in life cycle of the bridge due to the application of various improvement methods and figure 12 presents the comparison of the fatigue life cycles for different methods.

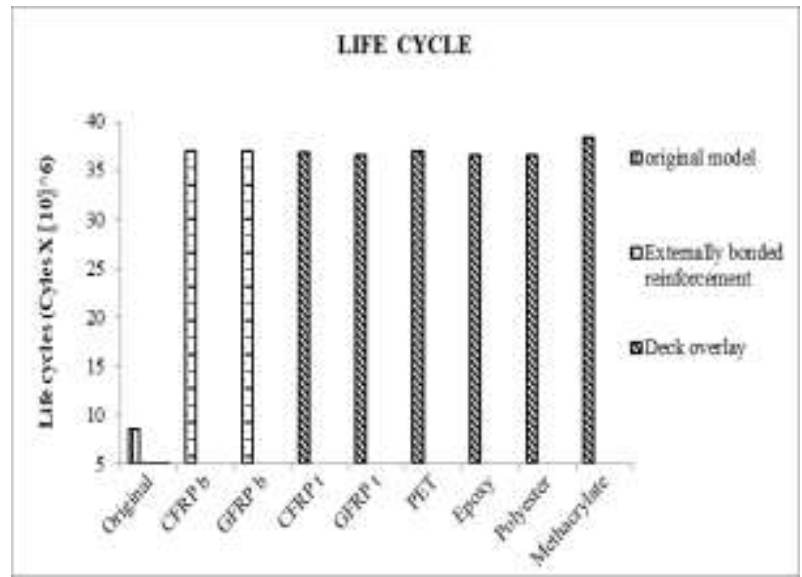

Fig. 11: Comparison of Life Cycle with Original Model.

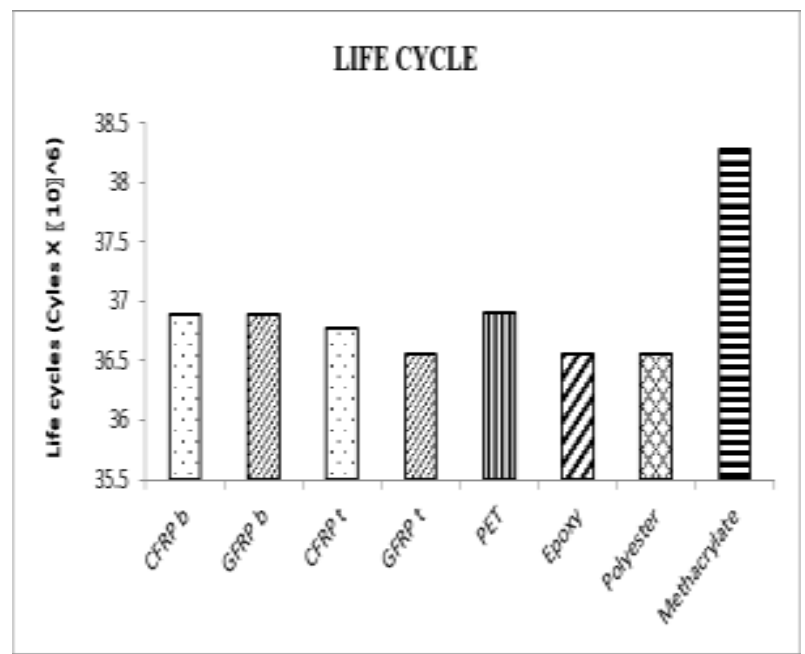

Fig. 12: Comparison of Fatigue Life Cycle of Improvement Methods.

\section{Conclusion}

This study demonstrates the assessment of fatigue life of highway bridges and evaluates the effectiveness of various improvement methods in enhancing its fatigue life. Our analysis on a case bridge suggests that the total cumulative damage on the case structure is 0.618 per year and the minimum fatigue life cycle of the bridge is approximately 8.4 million. In addition, the time of propagation of carbonation corrosion for $12 \mathrm{~mm}$ and $8 \mathrm{~mm}$ diameter bars is 84 and 125 years respectively. The study also applied various improvement methods suggested in the literature to enhance the fatigue life of the case bridge. The results indicate that application of bonded reinforcement and deck overlays with CFRP, GFRP, 
PET bottle waste and Polymeric concrete can improve fatigue life of highway bridges significantly.

In conclusion, this study proposes that methacrylate concrete overlay gives higher life cycle as compared to others and CFRP and GFRP show better performance as an external bonded reinforcement. Apart from this, use of PET bottle waste in deck overlays is both an economic and efficient way to enhance the fatigue life and reduce plastic waste. Table 8 shows the percentage increase in life cycle and stress reduction due to the improvement methods.

Table 8: Percentage Increase in Life Cycle and Stress Reduction Due to Improvement Methods

\begin{tabular}{|c|c|c|}
\hline Improvement methods & $\begin{array}{l}\text { Reduction in Stress I } \\
(\%)\end{array}$ & $\begin{array}{l}\text { Increase in Life } \\
\text { cycle }(\%)\end{array}$ \\
\hline $\begin{array}{l}\text { CFRP (externally bonded rein- } \\
\text { forcement) }\end{array}$ & 44.02 & 76.98 \\
\hline $\begin{array}{l}\text { GFRP (externally bonded rein- } \\
\text { forcement) }\end{array}$ & 44.03 & 76.99 \\
\hline CFRP (deck overlay) & 43.84 & 76.91 \\
\hline GFRP (deck overlay) & 43.51 & 76.78 \\
\hline PET bottle waste & 44.05 & 77 \\
\hline Epoxy concrete overlay & 43.51 & 76.78 \\
\hline Polyester concrete overlay & 43.50 & 76.77 \\
\hline Methacrylate concrete Overlay & 46.17 & 77.82 \\
\hline
\end{tabular}

\section{Acknowledgement}

This research did not receive any specific grant from funding agencies in the public, commercial, or not-for-profit sectors.

\section{References}

[1] AASTHO (American Association of State Highway and Transportation Officials) 2007. «AASTHO LRFD Bridge design specifications 4th edition ». American Association of State Highway and Transportation Officials, Washington DC.

[2] Bakis, Charles E, Ganjehlou, I. Kachlakev, Schupack, P. N. Balaguru, Duane J. Gee et al. 2002. "Guide for the design and construction of externally bonded FRP systems for strengthening concrete structures". Reported by ACI Committee. 440.

[3] Ellobody. 2011. "Performance of Composite Girders Strengthened Using Carbon Fiber Reinforced Polymer Laminates". Thin-Walled Structures.49 1429-1441.

[4] El-Ragaby, El-Salakawy, and Benmokrane. 2007. "Fatigue Life Evaluation of Concrete Bridge Deck Slabs Reinforced with Glass FRP Composite Bars". Journal of Composites for Construction. doi: 10.1061/(ASCE)1090-0260(2007)11:3(58)

[5] Gama.1999. "Durability of Epoxy Polymer Concrete Overlays for Bridge Decks". A thesis report McGill University.

[6] Habeeba A., Sabeena M.V., and Anjusha R. 2015. "Fatigue evaluation of Reinforced Concrete Highway Bridge". International Journal of Innovative Research in Science, Engineering and Technology.4 (4): 2561-2569.

[7] IRC (Indian Roads Congress): (6 - 2014). "Standard specifications and code of practice for road bridges section: ii loads and stresses (revised edition)". Indian Road Congress, New Delhi, India.

[8] IRC (Indian Roads Congress): (37 - 2012). "Tentative guidelines for the design of flexible pavements". Indian Road Congress, New Delhi, India.

[9] IRC (Indian Roads Congress): (SP 37 - 2010). "Guidelines for evaluation of load carrying capacity of bridges". Indian Road Congress, New Delhi, India.

[10] IRC (Indian Roads Congress): (SP 60 - 2002). "An approach document for assessment of remaining life of concrete bridges". Indian Road Congress, New Delhi, India.

[11] K. M. Mini, Alapatt, R. John, David, A. Elizabeth, Radhakrishnan A, Cyriac, M. Maria, and Ramakrishnan R. 2014. "Experimental study on strengthening of R.C beam using glass fiber reinforced composite". Structural Engineering and Mechanics.50: 275-286.

[12] Kong B., Cai C. S., and Kong X. 2013. "Thermal behaviors of concrete and steel bridges after slab replacements with GFRP honeycomb sandwich panels". Engineering Structures.56: 2041-2051.

[13] M. Puurula, Enochsson, Sas, Blanksvärd, Ohlsson, Bernspång, Taljsten, Carolin, Paulsson, and Elfgren. "Assessment of the Strengthening Of an RC Railway Bridge with CFRP Utilizing a Full-Scale Failure Test and Finite-Element Analysis". Journal of
StructuralEngineering. Doi: 10.1061/ $\quad$ (ASCE) ST.1943$541 \mathrm{X} .0001116$

[14] Seon Ji, Byun, Chang-Soo Lee, Byung-Jik Son, and John Ma Z. 2011. "Structural performance of composite sandwich bridge decks with hybrid GFRP-steel core". Composite Structures.93: 430-442.

[15] Theres N Kurian, Anna Varghese, and Divya K K. 2013. "Fatigue Analysis of Glass Fiber Reinforced Polymer (GFRP) Bridge Deck Panels". International Journal of Innovative Research in Science, Engineering and Technology 2 (1) 174-180.

[16] Verma and Arora.2015. "Replacement of natural sand in concrete by polyethylene bottles". International Research Journal of Engineering and Technology. 02 (01) 120-124.

[17] Wang, Deng, and Shao. 2016. "Fatigue design of steel bridges considering the effect of dynamic vehicle loading and overloaded trucks". Journal Bridge Engineering.21 (9). doi: 10.1061/(ASCE)BE.1943-5592.0000914.

[18] Yohannan and Susan Raj. 2015. "Finite element analysis of bridge deck slab". International Journal of Science, Engineering and Technology. 3 (5) : 1246-1248

[19] YongSheng and YouLiang. 2013. "Fatigue monitoring and analysis of orthotropic steel deck considering traffic volume and ambient temperature". Sci China Tech Sci. 56: 1758 1766. doi: 10.1007/s11431-013-5235-0.

[20] Zhang W., and Yuan H. 2014. "Corrosion fatigue effects on life estimation of deteriorated bridges under vehicle impacts". ELSEVIER Engineering Structures.71: 128-136. 